\title{
Decreased Maturation of Dendritic Cells in the Central Airways of COPD Patients Is Associated with VEGF, TGF- $\beta$ and Vascularity
}

\author{
Andrea Zanini ${ }^{a, b} \quad$ Antonio Spanevello ${ }^{a, b}$ Simonetta Baraldo ${ }^{c}$ Maria Majori ${ }^{d}$ \\ Sabrina Della Patrona ${ }^{b}$ Federico Gumiero $^{b}$ Marina Aiello $^{d}$ Dario Olivieri $^{d}$ \\ Marina Saetta ${ }^{c}$ Alfredo Chetta ${ }^{d}$ \\ a Department of Clinical and Experimental Medicine, University of Insubria, Varese, b Salvatore Maugeri Foundation, \\ Division of Pneumology, IRCCS Rehabilitation Institute of Tradate, Tradate, ' ${ }^{\circ}$ epartment of Cardiac, Thoracic and \\ Vascular Sciences, Section of Respiratory Diseases, University of Padua, Padua, and d Cardio-Nephro-Pulmonary \\ Department, Units of Respiratory Disease and Chest Endoscopy, University Hospital of Parma, Parma, Italy
}

\section{Key Words}

Chronic obstructive pulmonary disease - Dendritic cells ·

Angiogenic factors

\begin{abstract}
Background: Dendritic cells (DCs) have a pivotal role in the onset and regulation of innate and adaptive immune responses. Moreover, DCs can interact with angiogenic modulators, resulting in modification of their biology and participation in angiogenesis. Objectives: This study was designed to evaluate the relationship between the density of $D C s$, vascularity and expression of angiogenic factors [vascular endothelial growth factor (VEGF), transforming growth factor (TGF)- $\beta$ and basic fibroblast growth factor (bFGF)] in the central airways of chronic obstructive pulmonary disease (COPD) patients. Methods: The study included 20 patients with moderate/severe COPD and 8 healthy control subjects. Bronchial biopsies were evaluated by immunohistochemistry. Specimens were examined for CD83 and CD207 to mark mature and immature DCs, respectively, for collagen IV to evaluate vascularity, and for VEGF, TGF- $\beta$ and bFGF. Results: Compared to controls, COPD patients had a significant reduction
\end{abstract}

\section{KARGER}

E-Mail karger@karger.com

www.karger.com/res of CD83+ cells and an increased CD207/CD83 ratio $(p<0.05)$. Vascularity, VEGF, TGF- $\beta$ and bFGF were also significantly increased in COPD patients as compared to controls $(p<0.01)$. In COPD patients, CD83+ cells were inversely related to VEGF and TGF- $\beta$ expression $(p<0.05)$. Moreover, the CD207/CD83 ratio was positively related to VEGF, TGF- $\beta$ and vascularity $(p<0.05)$. Finally, CD207+ cells were inversely related to $\mathrm{FEV}_{1}$ $(p<0.05)$. Conclusion: Our results show a reduced maturation of DCs in COPD that was related to airway vascularity and angiogenic factors (VEGF and TGF- $\beta$ ). Additionally, immature DCs were significantly related to disease severity. We propose that the interplay between airway vascular changes, on one hand, and DCs maturation on the other, may play a key role in the pathogenetic mechanisms of COPD.

(c) 2014 S. Karger AG, Basel

\section{Introduction}

In recent years increasing importance has been given to the immunological aspects of chronic obstructive pulmonary disease (COPD) [1-3]. In this context, dendritic cells (DCs) perform a key role in the onset and regulation of
(C) 2014 S. Karger AG, Basel

0025-7931/14/0873-0234\$39.50/0
Dr. Andrea Zanini

Divisione di Pneumologia Fondazione Salvatore Maugeri, IRCCS

Via Roncaccio 16, IT-21049 Tradate (Italia)

E-Mail andrea.zanini@fsm.it 
innate and adaptive immune responses [4]. There are immature and mature DCs and at least three phenotypic and functional subsets [5]. DCs normally control immunologic homeostasis, but may behave inappropriately in COPD. Recent observations indicate an incomplete DC maturation process in the small airways of patients with COPD, with a decrease in mature (CD83+) DCs and an increase in langerin-expressing (CD207)+ DCs considered to be immature [6-8]. Moreover, active cigarette smoking was associated with decreased numbers of bronchial mucosal DCs expressing the maturation marker CD83 in induced sputum samples from COPD patients, and in endobronchial biopsies from asthmatic subjects [9-10].

Although the primary biological functions of DCs are the initiation and the regulation of specific immune responses, DCs also have the ability to regulate inflammatory responses through the release of cytokines and chemokines and the regulation of angiogenesis [11]. Importantly, DCs can produce and release various angiogenic factors and, in turn, angiogenic factors can affect the biology of DCs [11].

It has been reported that vascular changes may occur in the airways of COPD patients, even if this phenomenon seems to be less evident than in asthma $[12,13]$. Notably, an increased bronchial vascular area was a common feature in COPD patients, at least in part as a result of increased expression of vascular endothelial growth factor (VEGF) and transforming growth factor (TGF)- $\beta$ [14-16].

Up to now, there are no data regarding the nonimmunologic functions of DCs in COPD patients, such as the relationship between bronchial mucosal DCs and bronchial expression of angiogenic factors. Interestingly, there is evidence that angiogenesis may impact on the maturation process of DCs, particularly in the context of tumors. Indeed, production of VEGF by human tumor cells inhibits the functional maturation of DCs in vitro [17]. In vivo, in patients with lung cancer, an increase in VEGF expression has been reported $[18,19]$ and associated to increased microvessel density and decreased infiltration of DCs [18]. Of importance, patients with higher VEGF expression and a lower number of DCs showed a worse prognosis [18].

We hypothesized that the increased vascularity and angiogenic factors in the central airways of COPD patients may impact on the maturation of DCs. The aim of this study was, therefore, to quantify the number of mature (CD83+) and immature (CD207+) DCs in bronchial biopsies of COPD patients, and to evaluate the relationship between DC numbers, vascularity and angiogenic factors (VEGF, TGF- $\beta$ and basic fibroblast growth factor, bFGF). Furthermore, the relationship between these parameters and COPD severity was evaluated.

\section{Methods}

Subjects

We included COPD patients that were clinically stable and did not require long-term oxygen therapy. Twenty COPD patients were recruited from the Unit of Respiratory Disease and Lung Function of the Cardio-Nephro-Pulmonary Department, University Hospital of Parma. The patients had all been exsmokers for at least 10 years and had stable moderate-to-severe COPD, according to the GOLD classification [20]. All patients had been free from exacerbations in the previous 2 months and were nonatopic. Fourteen out of 20 COPD patients were under treatment with an inhaled long-acting bronchodilator (formoterol, salmeterol or tiotropium) and inhaled salbutamol as needed; the remaining 6 patients were under treatment with oral sustained-release theophylline and inhaled salbutamol as needed. Moreover, 10 out of 20 COPD patients were treated with combined long-acting bronchodilator treatment with inhaled corticosteroids [20]. At the time of the study all medications were continued as previously administered and required. All patients were nonatopic. Nonatopic, life-long nonsmoking volunteers were enrolled as a control group. The control subjects underwent fiber optic bronchoscopy for diagnostic reasons (6 subjects for cryptogenic hemoptysis and 2 for solitary peripheral nodule). The study was approved by the University of Parma ethical committee, and subjects gave written informed consent to enter the study. The study started in October 2011 and ended in February 2013.

\section{Study Design}

This study was a comparison study between COPD patients and control subjects. On 2 different study days the subjects included in the two groups underwent clinical and functional evaluation as well as fiber optic bronchoscopy. Subjects included in the two groups were recruited, sampled and analyzed concurrently.

\section{Fiberoptic Bronchoscopy}

Fiberoptic bronchoscopy was performed according to a previously described protocol [21]. Premedication consisted of atropine $(0.5 \mathrm{mg})$ and diazepam $(10 \mathrm{mg})$, both given by intramuscular injection. Local anesthesia was obtained with a tetracaine tablet $(20 \mathrm{mg})$ given 15 min before bronchoscopy. An additional aliquot of $2 \%$ lignocaine was aerosolized into the upper airways and applied topically to the pyriform sinuses and vocal cords to prevent coughing and as a local anesthetic. Nebulized salbutamol (1.25 mg) and ipratropium bromide $(0.25 \mathrm{mg})$ were administered 5 min prior to bronchoscopy (Model 1T10; Olympus, Tokyo, Japan). Three to five mucosal biopsy specimens were taken at the subcarina in the middle and lower lobes of the right lung. Administration of nebulized salbutamol and ipratropium bromide was repeated after bronchoscopy when necessary. Patients were closely monitored after bronchoscopy in the outpatient clinic, and were discharged when the effects of sedation disappeared and lung function returned to the baseline values. 


\section{Biopsy Processing}

Mucosal biopsies were immediately transferred into ice-cold acetone containing the protease inhibitor iodoacetamide $(20 \mathrm{mM})$ and phenylmethylsulfonyl fluoride $(2 \mathrm{mM})$ for fixation; they were then stored at $-20^{\circ} \mathrm{C}$ for $24 \mathrm{~h}$ and processed into the water-soluble resin, glycol methacrylate (Polysciences, Northampton, UK), for embedding [22]. Biopsies were considered suitable for examination when there was at least $2.0 \mathrm{~mm}$ of basement membrane length and $0.2 \mathrm{~mm}^{2}$ of subepithelial area.

Sections of $2 \mu \mathrm{m}$ were cut and incubated with primary antibodies for 16-20 h overnight at room temperature. We used monoclonal antibodies directed against CD83 to mark mature DCs (1:100; LifeSpan BioSciences, Seattle, Wash., USA) and langerin (CD207) to identify immature DCs (1:25; Dendritics, Lyon, France). Moreover, the expression of angiogenic factors was assessed using antibodies against VEGF (121, 165 and 189 isoforms of VEGF, 1:50; NeoMarkers, Fremont, Calif., USA), TGF $\beta$ (1:25; Novocastra Lab., Newcastle, UK), bFGF (1:25; BD Biosciences Pharmingen, San Jose, Calif., USA). Finally, the data on vascularity were assessed from a previous publication [16] using collagen IV to outline endothelial basement membrane (1:400; Novocastra Lab.). After washing in Tris-buffered saline, the sections were incubated for $2 \mathrm{~h}$ with biotin-conjugated secondary antibody (Vector Lab., Burlingame, Calif., USA). Light microscopy was performed with a Leica microscope (Leica DMLB, Werzlar, Germany) at 1,000× magnification.

As previously described [16], the number of cells positive for CD83, CD207, VEGF, TGF- $\beta$ and bFGF, as well as the number of vessels were quantified in all nonoverlapping high-power fields in the subepithelial lamina propria. The latter is defined as a zone $100 \mathrm{~m}$ below the epithelial basement membrane, and expressed as the number of cells per square millimeter of lamina propria. In each section, all available nonoverlapping high-power fields with intact tissue covered by intact basement membrane were examined. The vascular area was expressed as the percentage of the area of the assessed lamina propria. The mean size of vessels was estimated by dividing the total vascular area by the total number of vessels. Final values represent the mean of at least two sections from two different biopsies in each subject. The immunostaining for CD83 and CD207 was also evaluated in the bronchial epithelium, considering a range from 0 , as absence of immunostaining, to 3 , as extensive intense immunostaining. Basement membrane thickness was measured as described previously $[23,24]$. A single observer, who had no knowledge of patient characteristics, evaluated the tissue sections using an image analysis system (Image-Pro Plus; MediaCybernetics Inc., Silver Spring, Md., USA). An average of eight power fields were examined for each subject included in the study. The mean coefficient of variation for repeated measurements was $<10 \%$.

\section{Statistical Analysis}

Values are presented as mean \pm standard deviation (SD). Differences between groups were analyzed by the nonparametric Mann-Whitney $U$ test and $\chi^{2}$ test. Relationships were estimated by Spearman's rank correlation coefficient $\left(\mathrm{r}_{\mathrm{s}}\right)$. A p value $<0.05$ was taken as significant. Intraobserver variation was determined by counting the mean coefficient of variation for repeated measurements.
Table 1. Characteristics of COPD patients and control subjects

\begin{tabular}{lccl}
\hline & COPD $(\mathrm{n}=20)$ & Controls $(\mathrm{n}=8)$ & $\mathrm{p}$ \\
\hline Age, years & $76 \pm 10$ & $66 \pm 17$ & $\mathrm{n} . \mathrm{s.}$ \\
Sex (female/male) & $3 / 17$ & $5 / 3$ & 0.012 \\
FEV $_{1}, \%$ pred & $51 \pm 9$ & $104 \pm 22$ & 0.000 \\
FEV $_{1}$ /FVC, \% & $49 \pm 12$ & $76 \pm 3$ & 0.000 \\
TLC, \% pred & $114 \pm 20$ & $119 \pm 17$ & n.s. \\
RV, \% pred & $174 \pm 59$ & $112 \pm 23$ & 0.008 \\
RV/TLC, \% & $62 \pm 11$ & $35 \pm 15$ & 0.000 \\
\hline
\end{tabular}

Values are expressed as mean \pm SD.

\section{Results}

\section{Clinical Findings}

The characteristics of COPD patients and control subjects are reported in table 1 . In COPD patients, lung function values were recorded after bronchodilator administration. There was a male predominance among COPD patients, while females were more represented in the control group. Although the group of control subjects was slightly younger than the COPD cases, the difference did not reach the level of statistical significance. As expected from the selection criteria, the values of $\mathrm{FEV}_{1}$ and $\mathrm{FEV}_{1} / \mathrm{FVC}$ were significantly reduced in patients with COPD as compared to controls. Furthermore, the values of RV and RV/TLC were significantly increased in patients with COPD as compared to controls. Among patients with COPD, 8 had moderate disease and 12 had severe disease. Fiber optic bronchoscopy with endobronchial biopsy specimens was performed successfully and was well tolerated in all subjects.

\section{Morphological Findings}

In patients with COPD, DCs were mainly localized in the airway submucosa, sometimes in proximity to microvessels, but not directly adjacent to them (fig. 1). Conversely, the expression of CD83 and CD207 in the bronchial epithelium was very scanty (fig. 1). Data on the DC maturation profile, angiogenic factor expression and vascularity are summarized in table 2 .

The number of mature DCs in the submucosa (CD83+ cells) was significantly decreased in COPD patients, as compared to control subjects ( $\mathrm{p}<0.05$; table 2 ). The number of langerin (CD207)+ cells in the submucosa, considered to be immature DCs, although numerically increased in COPD patients, was not different compared to controls.

For each individual patient we also expressed the results as the ratio between immature and mature DCs 

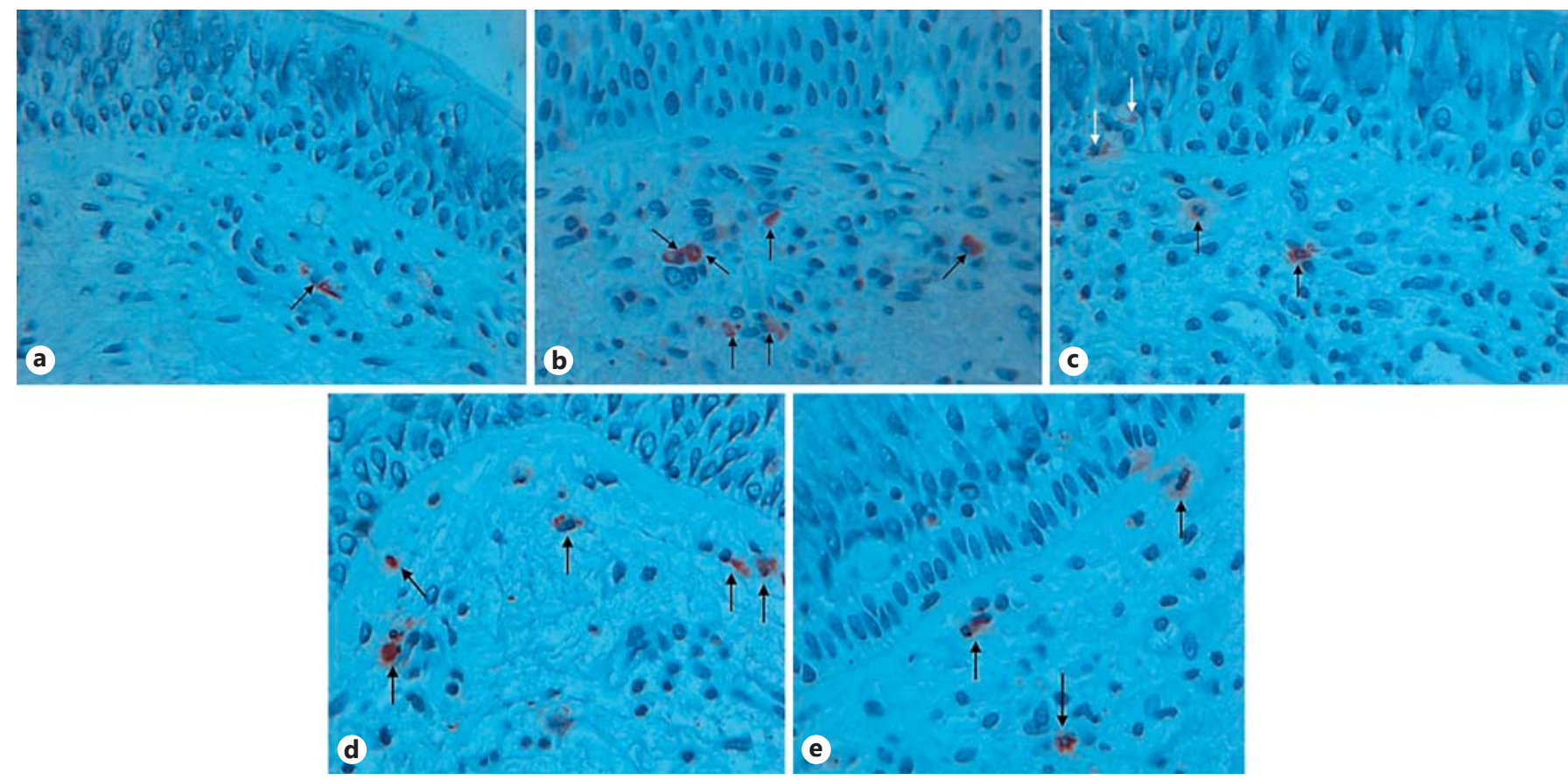

Fig. 1. Microphotographs from a COPD subject showing bronchial biopsies stained with antibody directed against CD83 (a) and CD207 $(\mathbf{b}, \mathbf{c}), \operatorname{VEGF}(\mathbf{d})$ and TGF- $\beta$ (e). Positive cells in the lamina propria are indicated by black arrows and those in the bronchial epithelium by white arrows. Original magnification $\times 400$.

Table 2. Expression of CD207+ cells, CD83+ cells and angiogenic factors in COPD patients and control subjects

\begin{tabular}{lccl}
\hline & COPD $(\mathrm{n}=20)$ & Controls $(\mathrm{n}=8)$ & $\mathrm{p}$ \\
\hline CD207+ cells $/ \mathrm{mm}^{2}$ & $48.9 \pm 11.4$ & $40.9 \pm 11$ & $\mathrm{n} . s$. \\
CD83+ cells $/ \mathrm{mm}^{2}$ & $1.13 \pm 0.48$ & $1.57 \pm 0.39$ & 0.034 \\
CD207/CD83+ cells & $55.7 \pm 36.7$ & $26.8 \pm 6.9$ & 0.010 \\
VEGF+ cells $/ \mathrm{mm}^{2}$ & $121 \pm 24.3$ & $82 \pm 9.2$ & 0.001 \\
TGF- $\beta+$ cells $/ \mathrm{mm}^{2}$ & $55.2 \pm 26.5$ & $9.6 \pm 2$ & 0.001 \\
bFGF+ cells $/ \mathrm{mm}^{2}$ & $49.7 \pm 10.3$ & $21.5 \pm 2.4$ & 0.001 \\
Vessels $/ \mathrm{mm}^{2}$ & $136 \pm 22$ & $117 \pm 13$ & 0.032 \\
Vascular area, $\%$ & $5.1 \pm 1.2$ & $3.9 \pm 0.5$ & 0.006 \\
Vessel size, $\mu \mathrm{m}^{2}$ & $385 \pm 58$ & $305 \pm 20$ & 0.001 \\
Basement membrane thickness, $\mu \mathrm{m}$ & $5.5 \pm 0.4$ & $5.1 \pm 0.3$ & 0.028 \\
Epithelial CD207+ cells score, $\%$ & $0.4 \pm 0.5$ & $0.37 \pm 0.52$ & $\mathrm{n} . \mathrm{s}$. \\
Epithelial CD83+ cells score, $\%$ & $0.35 \pm 0.49$ & $0.25 \pm 0.46$ & n.s. \\
\hline
\end{tabular}

Values are expressed as mean $\pm \mathrm{SD}$.

(CD207/CD83+ cells). We found that this ratio was markedly increased in COPD patients, in whom the median values were two times higher than those of control subjects. This imbalance in the maturation profile of DCs was paralleled by an increased expression of the proangiogenic factors examined. Indeed, the numbers of VEGF+ cells,
TGF- $\beta+$ cells (fig. 1 ) and bFGF $^{+}$cells were all significantly increased in COPD patients, as compared to control subjects ( $\mathrm{p}<0.001$ for each comparison). The vessel number, the vascular area and the vessel size were found to be increased in the airways of COPD patients when compared to controls (table 2). Moreover, COPD patients also 


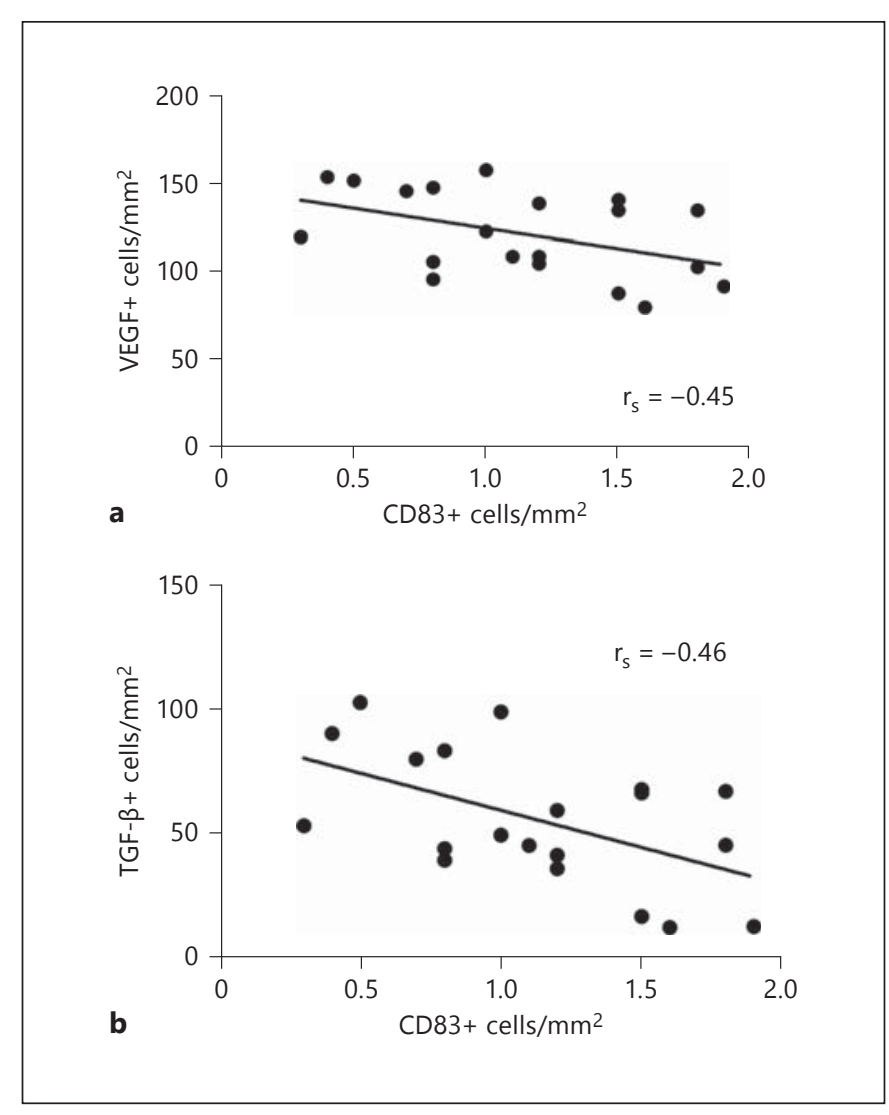

Fig. 2. Relationship between the number of CD83+ cells and the number of VEGF+ cells $\left(\mathrm{r}_{\mathrm{s}}=-0.45, \mathrm{p}<0.05 ; \mathrm{a}\right)$ and the number of TGF- $\beta+$ cells $\left(\mathrm{r}_{\mathrm{s}}=-0.46, \mathrm{p}<0.05 ; \mathbf{b}\right)$ in COPD patients.

Table 3. Results of Spearman's correlation analysis when all subjects included in the study are considered as one group

\begin{tabular}{|c|c|c|c|}
\hline & $\begin{array}{l}\text { CD83+ cells/ } \\
\mathrm{mm}^{2}\end{array}$ & $\begin{array}{l}\text { CD207+ cells/ } \\
\mathrm{mm}^{2}\end{array}$ & $\begin{array}{l}\text { CD207/ } \\
\text { CD83 }\end{array}$ \\
\hline \multirow[t]{2}{*}{$\mathrm{VEGF}+$ cells $/ \mathrm{mm}^{2}$} & $\mathrm{p}<0.001$ & $\mathrm{p}<0.05$ & $\mathrm{p}<0.001$ \\
\hline & $r_{s}=-0.61$ & $\mathrm{r}_{\mathrm{s}}=0.41$ & $r_{s}=0.69$ \\
\hline \multirow[t]{2}{*}{ TGF- $\beta+$ cells $/ \mathrm{mm}^{2}$} & $\mathrm{p}<0.01$ & $\mathrm{p}<0.05$ & $\mathrm{p}<0.001$ \\
\hline & $\mathrm{r}_{\mathrm{s}}=-0.56$ & $\mathrm{r}_{\mathrm{s}}=0.38$ & $r_{s}=0.64$ \\
\hline \multirow{2}{*}{$\mathrm{bFGF}+$ cells $/ \mathrm{mm}^{2}$} & $\mathrm{p}<0.05$ & n.s. & $\mathrm{p}<0.01$ \\
\hline & $r_{s}=-0.40$ & & $\mathrm{r}_{\mathrm{s}}=0.48$ \\
\hline \multirow[t]{2}{*}{ Vessels $/ \mathrm{mm}^{2}$} & $\mathrm{p}<0.01$ & n.s. & $\mathrm{p}<0.01$ \\
\hline & $\mathrm{r}_{\mathrm{s}}=-0.50$ & & $\mathrm{r}_{\mathrm{s}}=0.53$ \\
\hline \multirow[t]{2}{*}{ Vascular area, $\%$} & $\mathrm{p}<0.01$ & $\mathrm{p}<0.05$ & $\mathrm{p}<0.001$ \\
\hline & $r_{s}=-0.55$ & $\mathrm{r}_{\mathrm{s}}=0.41$ & $r_{s}=0.64$ \\
\hline \multirow[t]{2}{*}{ Vessel size, $\mu \mathrm{m}^{2}$} & $\mathrm{p}<0.001$ & $\mathrm{p}<0.05$ & $\mathrm{p}<0.001$ \\
\hline & $r_{s}=-0.59$ & $\mathrm{r}_{\mathrm{s}}=0.46$ & $r_{s}=0.68$ \\
\hline \multirow{2}{*}{$\begin{array}{l}\text { Basement membrane } \\
\text { thickness, } \mu \mathrm{m}\end{array}$} & n.s. & n.s. & $\mathrm{p}<0.05$ \\
\hline & & & $\mathrm{r}_{\mathrm{s}}=0.44$ \\
\hline \multirow[t]{2}{*}{$\mathrm{FEV}_{1}, \%$ pred } & n.s. & $\mathrm{p}<0.05$ & $\mathrm{p}<0.01$ \\
\hline & & $\mathrm{r}_{\mathrm{s}}=-0.43$ & $\mathrm{r}_{\mathrm{s}}=-0.51$ \\
\hline
\end{tabular}

had slightly higher, yet significant, values of basement membrane thickness ( $p<0.05$; table 2). Finally, the expression of CD83 and CD207 in the bronchial epithelium was not different between the two groups of subjects.

When steroid-treated COPD patients were compared to steroid-untreated COPD patients and to control subjects no difference was found in the number of CD83+ cells, CD207+ cells or the CD207/CD83 ratio (data not shown). Furthermore, the numbers of CD83+ and CD207+ cells were not related to the age and gender of the subjects included in our study (data not shown).

\section{Correlations}

When all subjects were considered together, a number of significant correlations were observed, which are described in table 3. Of interest, some of these correlations remained significant when considering only COPD patients. Indeed, the number of CD83+ cells correlated inversely with both VEGF expression and TGF- $\beta$ expression $\left(r_{s}=-0.45\right.$ and $r_{s}=-0.46$, respectively; fig. 2$)$. In addition the CD207/CD83 ratio correlated directly with the number of vessels $\left(r_{s}=0.51\right)$, the vascular area $\left(r_{s}=0.51\right)$ and vessel size $\left(r_{s}=0.56\right.$; fig. 3$)$, as well as with VEGF expression $\left(r_{s}=0.59\right)$ and TGF- $\beta$ expression $\left(r_{s}=0.58\right.$; fig. 4). Finally, the number of CD207+ cells in the airway wall of patients with COPD was inversely related to $\mathrm{FEV}_{1}$ values $\left(r_{s}=-0.52\right.$; fig. 5$)$.

\section{Discussion}

In this study we assessed the density and maturation profile of DCs in endobronchial biopsies of COPD patients, and examined the relationship with angiogenic growth factor expression. We showed that, in the large airways of COPD patients, there was a decreased number of mature DCs and an increased ratio of immature versus mature DCs, compared to control subjects. Of importance, we provided the first evidence that in COPD patients, the maturation profile of DCs was correlated with the vascularity of the bronchial wall and with the bronchial expression of VEGF and TGF- $\beta$. Finally, we found a correlation between the number of immature DCs and the severity of airflow obstruction.

Up to now, biopsy data concerning the expression of mature DCs in the airways of patients with COPD are very scanty, and there are no immunohistochemical studies tailored for examination of DCs in the central airway wall $[7,25]$. Tsoumakidou et al. [7] showed a significant reduction in CD83 molecule expression in small airways of pa- 


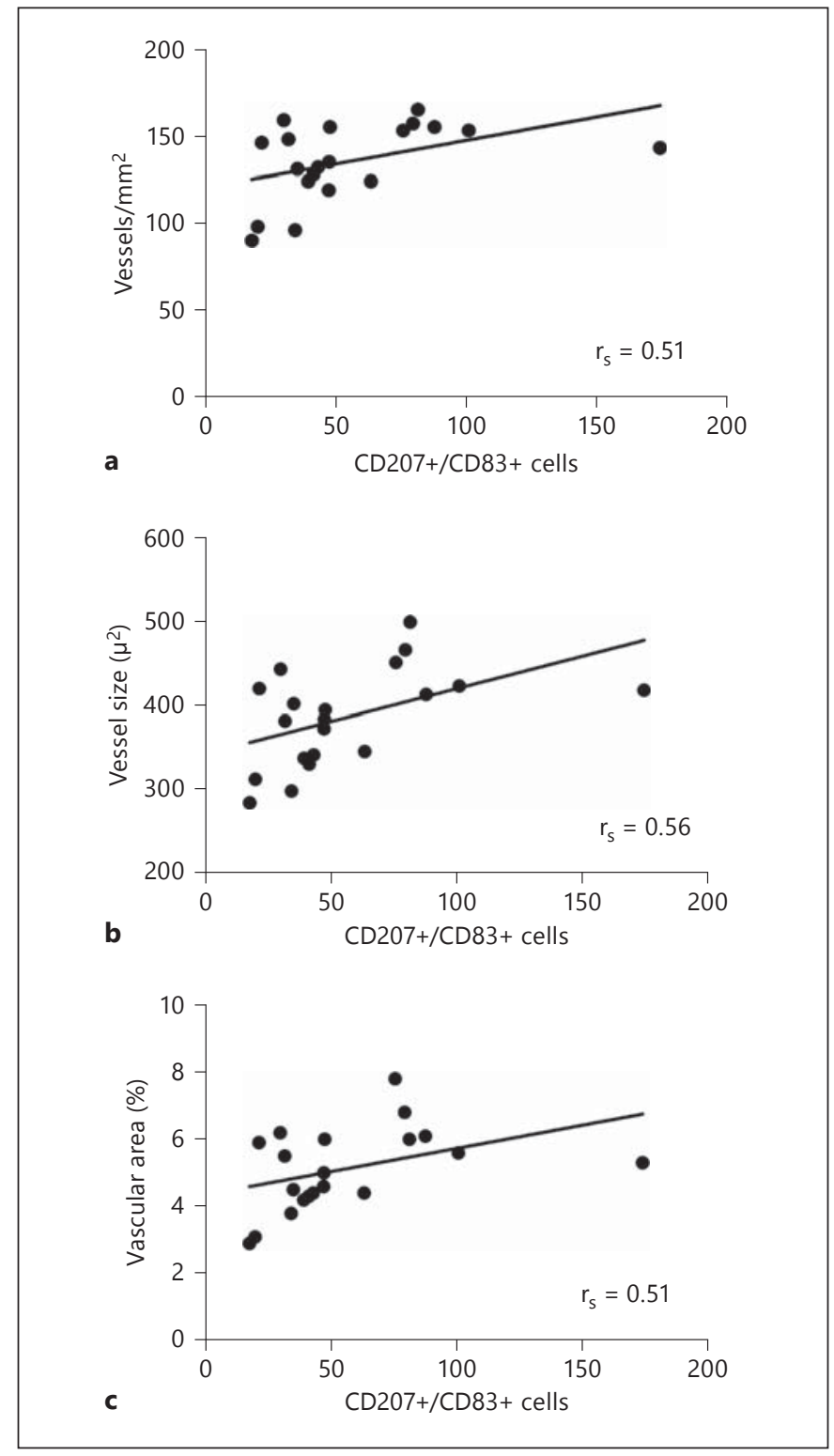

Fig. 3. Relationship between the CD207+/CD83+ cells ratio and the number of vessels $\left(r_{s}=0.51, p<0.05 ; a\right)$, the vessel size $\left(r_{s}=\right.$ $0.56, \mathrm{p}<0.05 ; \mathbf{b})$ and the vascular area $\left(\mathrm{r}_{\mathrm{s}}=0.51, \mathrm{p}<0.05 ; \mathbf{c}\right)$ in COPD patients.

tients with COPD, as compared to smokers and neversmokers without COPD. They quantified CD83 expression semiquantitatively and found that CD83+ cells were located mainly in subepithelial areas of the airway wall [7]. More recently, in induced sputum samples, the same group [9] confirmed that COPD patients showed a decrease in mature DC counts, which was present even in current smokers with normal lung function and was reversed by smoking cessation. In a previous study in which

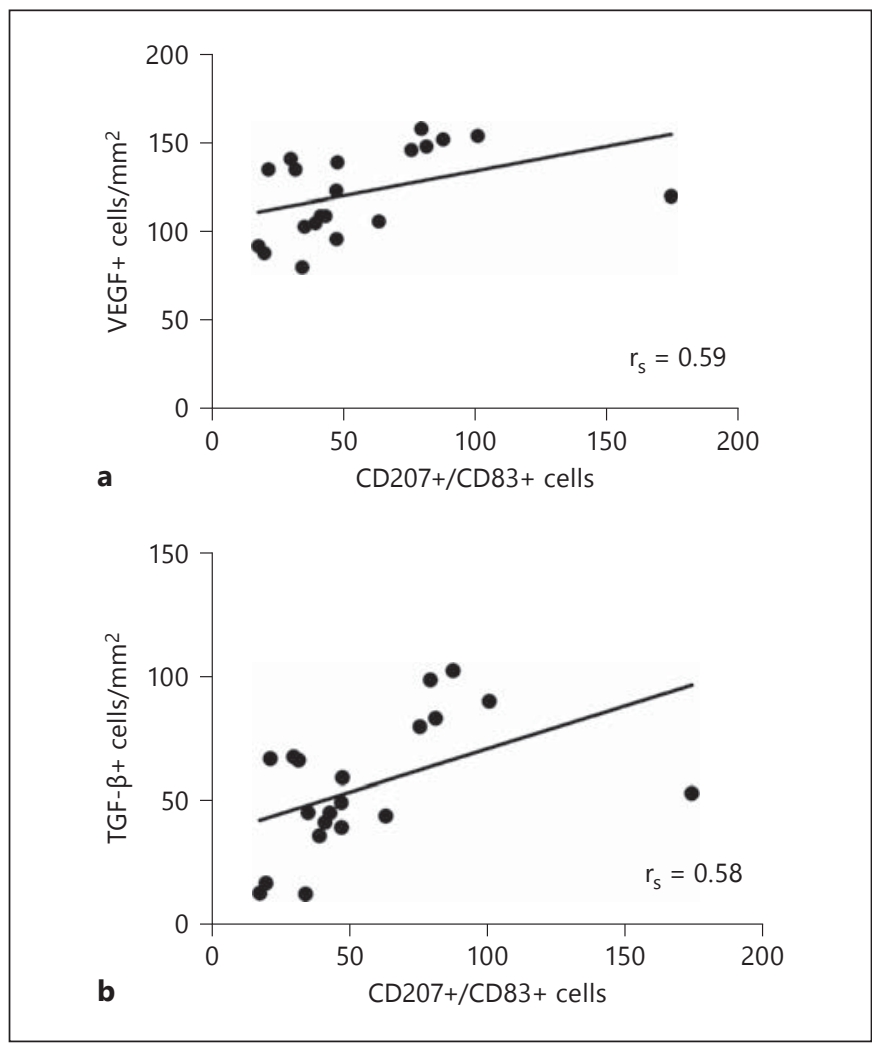

Fig. 4. Relationship between the CD207+/CD83+ cells ratio and the number of VEGF+ cells $\left(\mathrm{r}_{\mathrm{s}}=0.59, \mathrm{p}<0.01 ; \mathbf{a}\right)$ and the number of TGF- $\beta+$ cells $\left(r_{s}=0.58, p<0.01 ; \mathbf{b}\right)$ in COPD patients.

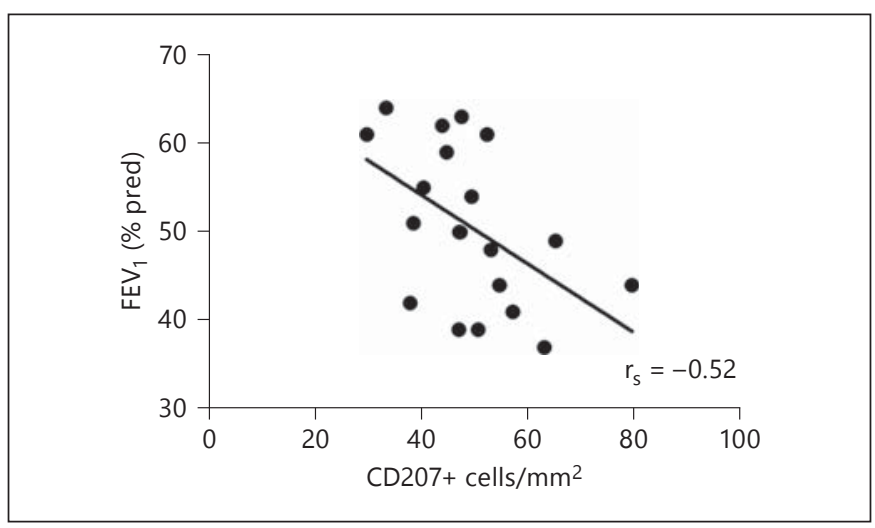

Fig. 5. Relationship between the number of CD207+ cells and $\mathrm{FEV}_{1}\left(\mathrm{r}_{\mathrm{s}}=-0.52, \mathrm{p}<0.05\right)$ in COPD patients.

mature DCs were identified by electron microscopy, current smokers with COPD showed a decreased number of bronchial mucosal DCs in bronchial biopsies [25]. Based on a quantitative analysis, we confirmed and extended those previous findings. It is also of note that our patients 
had all been ex-smokers for at least 10 years, thus avoiding active smoking as a possible direct cause of decrease in mature DC density. Conversely, Freeman et al. [26], using flow-cytometry on mechanically isolated lung leukocytes, showed that lung DC expression of maturation molecules increased with the worsening of COPD. This apparent disparity in results is likely related to the considerable difference in the compartments of the lung sampled. Indeed, it is worth considering that in our study we examined only mature DCs present in the airways, while in their report Freeman et al. [26] examined DCs from whole lungs. Since it is known that mature DCs move rapidly to draining lymph nodes, it is possible that the reduced CD83 expression observed in our study, together with the increase in their study, may reflect an enhanced trafficking of DCs to lymphoid structures in COPD patients.

Conversely, a significant increase of langerin-expressing (CD207) + DCs has been observed in the small airways of patients with COPD and was associated with upregulation of CCL20 [6, 27, 28], the most potent chemokine in attracting DCs. Moreover, the number of langerin+ DCs infiltrating the small airways increased progressively along with increasing severity of the disease, a finding that we confirmed in our study in bronchial biopsies. CD207+ cells have been traditionally considered as immature DCs since CD207 is downregulated upon DC maturation; however, recent work showed that CD207 may still be expressed after DC maturation, at least by some DC subtypes [8]. Nevertheless, we believe that, taken together, the previous findings and our data support the view that an imbalance between immature and mature DCs is present in both the large and small airways of smokers with COPD and may play an important pathogenetic role.

The mechanisms guiding DC maturation in the lungs of COPD patients have not been fully investigated, but are likely to involve structural cells of the compartments that DCs move through while travelling from the circulation to the airways to the regional lymph nodes. Of interest, there is recent in vitro evidence that fibroblasts have a crucial role in modulating DC trafficking in the airways through the release of TGF $\beta$, and that this mechanism is dysregulated in COPD [29]. In the present study, we provided the first in vivo indication of a relationship between the maturation profile of DCs and microvascularity, VEGF and TGF expression in the airways of patients with COPD. Notably, DCs may come into play in the regulation of inflammatory responses through their ability to release cytokines and chemokines and to regulate angiogenesis [11]. Interestingly, most of the studies relat- ing angiogenic factors and DCs have been performed in the context of immune regulation by tumors. In vitro and in vivo studies in lung cancer $[17,19]$ support the view that angiogenic factors could adversely affect the process of maturation of DCs, thereby impairing the immune response. Bergeron et al. [19] showed very few CD83+ cells in the connective stroma of lung carcinomas, indicating that most of the DC subsets infiltrating these tumors were immature DCs. Moreover, mRNAs coding for VEGF, TGF- $\beta$ and IL-10 were expressed in all lung cancer specimens, the potent inhibitory effect of these angiogenic factors on DC maturation being known [19]. Of importance, the expression of VEGF and the impaired maturation of DCs had a negative prognostic value in patients with cancer, highlighting the clinical relevance of this association. Of note, in this study, we found a relationship between airflow obstruction, expressed as $\mathrm{FEV}_{1}$, and the immature DC cell number in the bronchial mucosa of COPD patients. Our data are in line with previous reports $[6,27]$, which in large cohorts of COPD patients found that the number of immature DCs infiltrating the wall of the small airways increased along with the severity of COPD, as expressed by a worsening of airflow obstruction. Ours and previous data suggest that DCs significantly participate in the process of chronic airway inflammation that takes place in COPD, and that this process can be modulated by airway structural changes, particularly remodeling of the vascular bed. We should acknowledge, however, that the correlations in our study linking the expression of angiogenic growth factors and airway vascularity to DC subsets only explain part of the variability observed, pointing to the existence of other factors that may influence DC maturation. Among these, regulatory signals from the airway epithelium, which were not examined in the present study, are certainly important players. Furthermore, we should acknowledge that TGF- $\beta$ is a pleiotropic cytokine, with many anti-inflammatory and immune-suppressive, but also proinflammatory, activities. Indeed, TGF- $\beta$ is well known for its regulatory activities in autoimmune diseases, dampening immune responses and inducing peripheral tolerance to protect from tissue damage, but may also promote its amplification of immune responses by inducing Th17 cells [30]. Moreover, we acknowledge that the correlations between CD83 and the growth factors VEGF and TGF- $\beta$ are not particularly high. In this regard, it is likely that other mechanisms may be involved. Interestingly, Roghanian et al. [31] observed that neutrophil elastase in lung inflammatory secretions of patients with COPD may disable DCs and prevent them 
from mounting an adequate immune response. Given the complexity of the relationship between angiogenesis, DCs and regulation of immune responses in COPD and lung cancer, a specific evaluation of the underlying mechanisms deserves further investigation.

There are some potential criticisms in our study. Firstly, we acknowledge that our study is essentially descriptive, and functional studies designed to provide the mechanistic explanation for the observed alterations in DCs of COPD patients are needed. Another limitation of our report is the low power of the study because of the small number of subjects in each group. However, a low number of subjects and a low number of biopsies per subject are common limitations in biopsy studies. Finally, the use of inhaled corticosteroids, especially in the most severe stages of COPD, could influence DC numbers and differentiation, even if it has been shown that inhaled corticosteroids did not affect at least the number of immature DC cells in bronchial biopsies of COPD patients [32]. Despite all of these limitations, we believe that studies on bronchial biopsies provide a unique opportunity to investigate the complex relationship between airway inflammation and remodeling in COPD.

In conclusion, our study shows a reduced maturation of DCs in bronchial biopsies from large airways of COPD patients. Moreover, we have shown that the maturation profile of DCs is strictly associated with the number of vessels and the expression of angiogenic factors such as VEGF and TFG- $\beta$, suggesting that angiogenesis in the airway wall might be associated with altered trafficking of DCs in the lungs. Finally, we also demonstrated that this alteration is of clinical importance since an immature DC number correlates with worsening of airflow obstruction among COPD patients.

\section{Acknowledgments}

The authors would like to thank Mrs. Iris Spanevello for the valuable help in the biopsy processing. This work was supported by Cariparo Foundation-project of Excellence 2008.

\section{References}

1 Cosio MG, Saetta M, Agusti A: Immunologic aspects of chronic obstructive pulmonary disease. N Engl J Med 2009;360:2445-2454.

$>2$ Baraldo S, Turato G, Saetta M: Pathophysiology of the small airways in chronic obstructive pulmonary disease. Respiration 2012;84:89-97.

$>3$ Van Eeden ST, Hogg JC: Chronic obstructive pulmonary disease: do regional differences in tissue inflammation matter? Respiration 2011;81:359-361.

-4 Vermaelen K, Pauwels R: Pulmonary dendritic cells. Am J Respir Crit Care Med 2005;172: 530-551.

5 Tsoumakidou M, Demedts IK, Brusselle GG, Jeffery PK: Dendritic cells in chronic obstructive pulmonary disease: new players in and old game. Am J Respir Crit Care Med 2008; 177:1180-1186.

$\checkmark 6$ Demedts IK, Bracke KR, Van Pottelberge GV, Testelmans D, Verleden GM, Vermassen FE, Joos GF, Brusselle GG: Accumulation of dendritic cells and increased CCL20 levels in the airways of patients with chronic obstructive pulmonary disease. Am J Respir Crit Care Med 2007;175:998-1005.

-7 Tsoumakidou M, Koutsopoulos AV, Tzanakis N, Dambaki K, Tzortzaki E, Zakynthinos S, Jeffery PK, Siafakas NM: Decreased small airway and alveolar CD83+ dendritic cells in COPD. Chest 2009;136:726-733.

$\checkmark 8$ Romani N, Clausen BE, Stoitzner P: Langerhans cells and more: langerin-expressing dendritic cell subsets in the skin. Immunol Rev 2010;234:120-141.
-9 Tsoumakidou M, Bouloukaki I, Koutala H, Kouvidi K, Mitrouska I, Zakynthinos S, Tzanakis N, Jeffery PK, Siafakas NM: Decreased sputum mature dendritic cells in healthy smokers and patients with chronic obstructive pulmonary disease. Int Arch Allergy Immunol 2009;150:389-397.

$>10$ Tsoumakidou M, Elston W, Zhu J, Wang Z, Gamble E, Siafakas NM, Barnes NC, Jeffery PK: Cigarette smoking alters bronchial mucosal immunity in asthma. Am J Respir Crit Care Med 2007;175:919-925.

-11 Sozzani S, Rusnati M, Riboldi E, Mitola S, Presta M: Dendritic cell-endothelial cell cross-talk in angiogenesis. Trends Immunol 2007;28:385-392

12 Zanini A, Chetta A, Imperatori A, Spanevello A, Olivieri D: The role of the bronchial microvasculature in the airway remodelling in asthma and COPD. Respir Res 2010;11:132.

13 Chetta A, Zanini A, Torre O, Olivieri D: Vascular remodelling and angiogenesis in asthma: morphological aspects and pharmacological modulation. Inflamm Allergy Drug Targets 2007;6:41-45.

14 Hashimoto M, Tanaka H, Abe S: Quantitative analysis of bronchial wall vascularity in the medium and small airways of patients with asthma and COPD. Chest 2005;127: 965-972.

15 Calabrese C, Bocchino V, Vatrella A, Marzo C, Guarino C, Mascitti S, Tranfa CME, Cazzola M, Micheli P, Caputi M, Marsico SA: Evidence of angiogenesis in bronchial biop- sies of smokers with and without obstruction. Resp Med 2006;100:1415-1422.

16 Zanini A, Chetta A, Saetta M, Baraldo S, Castagnetti C, Nicolini G, Neri M, Olivieri D: Bronchial vascular remodelling in patients with COPD and its relationship with inhale steroid treatment. Thorax 2009;64:1019-1024.

17 Gabrilovich DI, Chen HL, Girgis KR, Cunningham HT, Meny GM, Nadaf S, Kavanaugh D, Carbone DP: Production of vascular endothelial growth factor by human tumors inhibits the functional maturation of dendritic cells. Nat Med 1996;2:1096-1103.

18 Inoshima N, Nakanishi Y, Minami T, Izumi M, Takayama K, Yoshino I, Hara N: The influence of dendritic cell infiltration and vascular endothelial growth factor expression on the prognosis of non-small cell lung cancer. Clin Cancer Res 2002;8:3480-3486.

19 Bergeron A, El Hage F, Kambouchner M, Lecossier D, Tazi A: Characterisation of dendritic cell subsets in lung cancer micro-environments. Eur Respir J 2006;28:1170-1177.

20 Global Initiative for Chronic Obstructive Lung Disease (GOLD): Global strategies for the diagnosis, management and prevention of chronic pulmonary disease. 2011. http:// www.goldcopd.org/guidelines.

21 Chetta A, Zanini A, Foresi A, D’Ippolito R, Tipa A, Castagnaro A, Baraldo S, Neri M, Saetta M, Olivieri D: Vascular endothelial growth factor upregulation and bronchial wall remodelling in asthma. Clin Exp Allergy 2005;35:1437-1442. 
22 Britten KM, Howarth PH, Roche WR: Immunohistochemistry of resin sections, a comparison of resin embedding techniques for small mucosal biopsies. Biotech Histochem 1993; 68:271-280.

23 Sullivan P, Stephens D, Ansari T, Costello J, Jeffery PK: Variation in the measurements of basement membrane thickness and inflammatory cell number in bronchial biopsies. Eur Respir J 1998;12:811-815.

24 Chetta A, Zanini A, Foresi A, Del Donno M, Castagnaro A, D'Ippolito R, Baraldo S, Testi $\mathrm{R}$, Saetta M, Olivieri D: Vascular component of airway remodeling in asthma is reduced by high dose of fluticasone. Am J Respir Crit Care Med 2003;167:751-757.

-25 Rogers AV, Ädelroth E, Hattotuwa K, Dewar A, Jeffery PK: Bronchial mucosal dendritic cells in smokers and ex-smokers with COPD: an electron microscopic study. Thorax 2008; 63:108-114.
26 Freeman CM, Martinez FJ, Han MK, Ames TM, Chensue SW, Todt JC, Arenberg DA, Meldrum CA, Getty C, McCloskey L, Curtis JL: Lung dendritic cell expression of maturation molecules increases with worsening chronic obstructive pulmonary disease. Am J Respir Crit Care Med 2009;180:1179-1188.

27 Van Pottelberge GR, Bracke KR, Demedts IK, De Rijck K, Reinartz SM, van Drunen CM, Verleden GM, Vermassen FE, Joos GF, Brusselle GG: Selective accumulation of langerhans-type dendritic cells in small airways of patients with COPD. Respir Res 2010;11:35.

28 Shan M, Cheng HF, Song LZ: Lung myeloid dendritic cells coordinately induce $\mathrm{T}_{\mathrm{H}} 1$ and $\mathrm{T}_{\mathrm{H}} 17$ responses in human emphysema. Sci Transl Med 2009;1:4ra10.
9 Kitamura H, Cambier S, Somanath S, Barker T, Minagawa S, Markovics J: Mouse and human lung fibroblasts regulate dendritic cell trafficking, airway inflammation, and fibrosis through integrin $\alpha v \beta 8$-mediated activation of TGF- $\beta$. J Clin Invest 2011;121:2863-2875.

30 Sanjabi S, Zenewicz LA, Kamanaka M, Flavell RA: Anti-inflammatory and pro-inflammatory roles of TGF- $\beta$, IL-10, and IL-22 in immunity and autoimmunity. Curr Opin Pharmacol 2009;9:447-453.

31 Roghanian A, Drost EM, MacNee W, Howie SEM, Sallenave J-M: Inflammatory lung secretions inhibit dendritic cell maturation and function via neutrophil elastase. Am J Respir Crit Care Med 2006;174:1189-1198.

32 Verhoeven GT, Hegmans JPJJ, Mulder PGH, Bogaard JM, Hoogsteden HC, Prins JB: Effects of fluticasone propionate in COPD patients with bronchial hyperresponsiveness. Thorax 2002;57:694-700. 